\title{
Uma nova espécie de Euglosssa (Euglossella) Moure do Nordeste do Brasil (Hymenoptera, Apidae) ${ }^{1}$
}

\author{
Jesus Santiago Moure ${ }^{2}$ \\ Clemens Schlindwein ${ }^{3}$
}

\begin{abstract}
A new species of Euglossa (Euglossella) Moure from the Northeastern Brazil (Hymenoptera, Apidae). A really beautiful Euglossinae bee, Euglosssa (Euglossella) perpulchra sp. n., is decribed from Pernambuco, Igarassu, Brazil. It can be recognized by the following characters: head and thorax bronzeous green covered with fulvous pubescence, and abdomen bluish with white marginal bands narrowed progressively from second to sixth tergum; wings slightly fulvous, stigma and wing venation light fulvous. It is closely related to $E$. decorata Smith, 1874 and E. singularis Mocsáry, 1899.
\end{abstract}

KEY WORDS. Hymenoptera, Apidae, Euglossa (Euglossella), Neotropical, taxonomy

Esta abelha assemelha-se bastante à Euglossa (Euglossella) decorata Smith, 1874, descrita de St. Paul (atual São Paulo de Olivença, Amazonas), no extremo oeste da Amazônia brasileira. Distingue-se facilmente pela cor azul-aço do abdome, um pouco para o violáceo, ornado em cada segmento por uma larga faixa branca muito destacada, estreitada para os lados e progressivamente mais estreita do primeiro ao sexto tergo; o sétimo inteiramente preto, como as tíbias posteriores, distalmente. A cabeça e tórax de um ocre-brônzeo-claro com desenhos brancos na face e densa pilosidade inteiramente fulvo-clara. A outra espécie próxima, do mesmo grupo e igualmente descrita da Amazônia, é Euglossa (Euglossella) singularis Mocsáry, 1899, que é facilmente separável pela abundante pilosidade preta do tórax. A espécie Euglossa meliponoides Ducke, 1902, corresponde à Euglossa singularis Mocsáry, 1899. A causa da omissão de referência à espécie de MOCSÁRY (1899), por DUCKE (1902), é facilmente explicável, pois, o trabalho de MOCSÁRY (1899) está como um apêndice ao de FRIESE (1899), em sua monografia, sem destaque especial.

A referência que SMITH (1874) faz ao abdome de $E$. decorata é extremamente breve: "abdomen ferruginous at the base, becoming dark fuscous at the apex; the fourth and fifth segments have their apical margins fasciated with white pubescence; pale ferruginous beneath, the segments fringed with white pubescence.".

Os valores entre "( )" estão em centésimos de milímetro, a não ser com indicação contrária. A abreviação "dp" (= diâmetro de ponto) serve para indicar o tamanho dos intervalos entre os pontos, "d" indica diâmetro e "T" tergo.

1) Contribuição número 1333 do Departamento de Zoologia, Universidade Federal do Paraná.

2) Departamento de Zoologia, Universidade Federal do Paraná. Caixa Postal 19020, 81531-980 Curitiba, Paraná, Brasil. Bolsista do CNPq.

3) Departamento de Botânica, Universidade Federal de Pernambuco. Avenida Prof. Moraes Rêgo, 50670-901 Recife, Pernambuco, Brasil. Bolsista do CNPq. 


\section{Euglossa (Euglossella) perpulchra sp. $\mathbf{n}$.}

Figs 1,2

Macho. Cabeça e tórax fulvo-brônzeos; face com as estrias orbitais inferiores esbranquiçadas e alargadas para baixo e largamente unidas às clípeo-laterais inferiores; mancha malar pequena e afastada dos bordos anterior e posterior; escapo pardo-ferrugíneo-claro com uma fraca estria pálida, o flagelo um pouco acastanhado com os dois segmentos basais levemente avermelhados; mandíbulas pretas, com os dois terços basais brancos; labro branco-méleo com estreita margem distal preta, com as áreas ovais translúcidas grandes (50:40), mais afastadas do bordo distal do que da base (35:85); pernas anteriores e médias de um fulvo-brônzeo-negro com alguns desenhos claros, com uma estria pardo-amarelada nas tíbias anteriores; tíbias posteriores negro-brônzeas no terço basal e negro-brilhantes na porção apical; os tarsos posteriores negro-brônzeos quase pretos. Abdome azul-aço-claro com faixas brancas marginais largas nos dois primeiros tergos, estreitadas progressivamente até o sexto; o sétimo de um brônzeo-negro-brilhante.

Pilosidade na cabeça e tórax fulva; na metade inferior dos mesepisternos e ventralmente esbranquiçada, desta mesma cor nas genas e nas pernas, com poucos pêlos escuros a pretos nas tíbias e tarsos anteriores e na face ventral dos basitarsos médios e posteriores; branca em todo lado ventral do tórax e abdome. Lado externo das tíbias médias com a área aveludada bem definida, com um triângulo glabro liso apical; coxins unidos em um só (30:50), subtriangular, com a ponta inferior um pouco em ogiva; basitarsos médios, na base alargados para trás em projeção angular e, aí, na face interna, com três grossas cerdas catarótricas

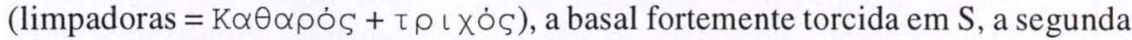
menos e a terceira quase reta. A fímbria posterior, das tíbias do último par, branca, com cerdas de até $800 \mu \mathrm{e}$, na face externa, muito esparsas, curtas e negras.

A pontuação forte e densa, pilígera, mais grossa no clípeo que na fronte, com a carena média muito forte e completa, as laterais um pouco menos, pouco divergentes nos dois terços basais, inferiormente bastante abertas e quase apagadas no terço apical; nas paroculares, com pequena área lisa junto aos alvéolos. $\mathrm{Na}$ área supraclipeal, mais fraca e igualmente densa; na fronte, densa e um pouco maior que na supraclipeal, mais grossa para os lados e para cima no limite das arcadas supralveolares fracamente marcadas; na fronte, acima das arcadas, um pouco mais fina e aumentando em tamanho junto aos ocelos; no vértice, bastante fina e densa entre os ocelos, deixando largas áreas lisas na frente dos mesmos; bastante fina nas genas, menos uma série de pontos grossos, esparsos, acompanhando a órbita. No mesoscuto e escutelo mais fina (cerca de 30-40 $\mu$ ), os intervalos lisos com cerca de $1 \mathrm{~d}$ p ou pouco menos, porém um pouco mais densa e mais grossa atrás; no escutelo com intervalos quase careniformes; nos mesepisternos, semelhante à do mesoscuto. Fina e esparsa na área basal do propódeo com os intervalos micro-reticulados. Nos tergos, claramente mais fina que no mesoscuto e os intervalos basais quase $2 \mathrm{dp}$ e um pouco mais adensada para trás; os tergos quinto e sexto com pontuação semelhante à dos anteriores; no sétimo tergo

Revta bras. Zool. 19 (2): 585 - 588, 2002 

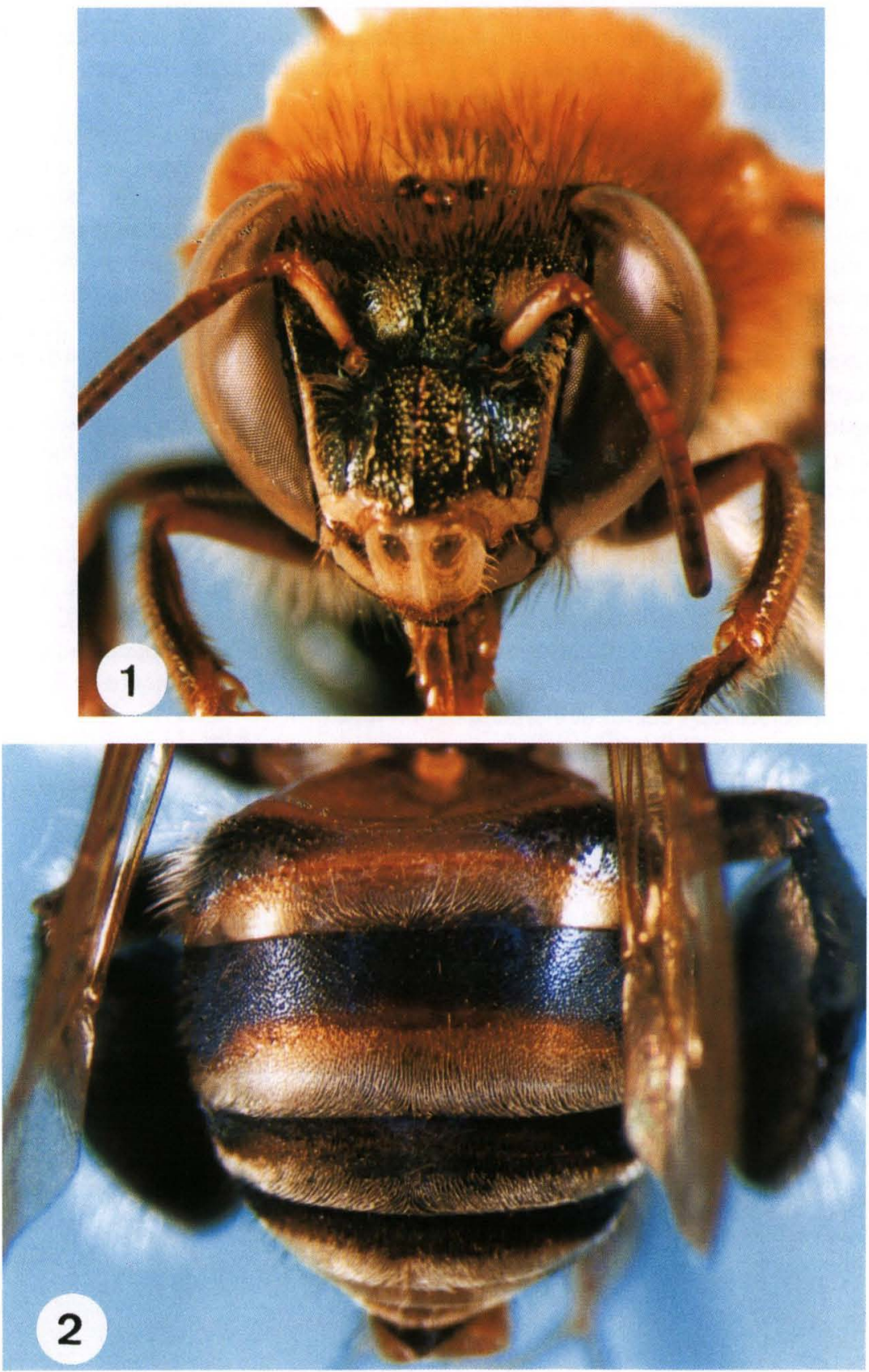

Figs 1-2. Euglossa (Euglossella) perpulchra sp. n. (1) Cabeça, vista anterior; (2) abdome, vista dorsal.

Revta bras. Zool. 19 (2): 585 - 588, 2002 
os pontos um pouco maiores e mais esparsos para a base. Na face externa das tíbias posteriores, muito esparsa em direção ao sulco glandular e para o ápice; mais fina e tão esparsa nos basitaros do mesmo par.

Cabeça mais larga que longa (480:330). Olho um pouco mais longo que duas vezes sua largura (330:150); interorbital máxima mais curta que o comprimento do olho, as interorbitais superior, mediana e inferior como (230:280:210); distâncias interocelares 70:30:d35. Mandíbulas tridentadas, com o segundo dente muito reduzido, às vezes, quase faltando na mandíbula direita. O escapo (90:d37) um pouco mais longo que o primeiro flagelômero e o seguinte juntos $(60+20)$, o terceiro tão longo como o segundo e seu diâmetro ligeiramente maior que seu comprimento (20:22). Escutelo, atrás, em arco fracamente rebaixado (140:260). Propódeo sem área basal definida. T1 sem rebordo na cavidade basal e esta pardo-clara. Abdome azul, fracamente metálico, um pouco para o violáceo, em T2 a faixa esbranquiçada cerca de 800 centésimos de milímetros no meio e estreitada para os lados, as seguintes progressivamente mais estreitas; o sétimo inteiramente azul-aço-preto.

Holótipo macho. Brasil, Pernambuco: Igarassu (Reserva Ecológica Charles Darwin), Schlindwein e Martini leg.". Parátipos: quatro machos, com os mesmos dados do holótipo. O material-tipo encontra-se depositado na Coleção de Entomologia J.S. Moure, Departamento de Zoologia, Universidade Federal do Paraná, Curitiba, Paraná. Vários outros exemplares no Departamento de Botânica, Universidade Federal de Pernambuco, Recife.

AGRADECIMENTO. Os autores agradecem ao Prof. Dr. Albino Morimasa Sakakibara pelas fotografias e leitura crítica do trabalho.

\section{REFERÊNCIAS BIBLIOGRÁFICAS}

DuCKe, A. 1902. As espécies paraenses do gênero Euglossa. Bol. Mus. Paraense Emílio Goeldi 3: 561-577.

FrIESE, H. 1899. Monographie der Bienengattung Euglossa. Természetrajzi Füzeteck 22: 142-172. MoCSÁRY, A. 1899. In: H. FrIESE. Monographie der Bienengattung Euglossa. Természetrajzi Füzeteck 22: 171-172.

Smith, F. 1874. A Revision of the Genera Epicharis, Centris, Eulaema and Euglossa, belonging to the Family Apidae. Section Scopulipedes. Section Corbiculipedes. Annals Magaz. Nat. His. 13 (4): 318-322, 357-373, 440-446.

Recebido em 07.XII.2001; aceito em 21.V.2002. 